\title{
Enhanced Mechanical Properties of Single-Domain YBCO Bulk Superconductors Processed With Artifi- cial Holes
}

\author{
T. Hlásek, K.Y. Huang, J. Esnoz-Larraya, V. Plecháček, J. H. Durrell, I. Valiente-Blanco, D.A. Cardwell
}

\begin{abstract}
Single domain YBCO bulk superconductors were prepared using a conventional top-seeded melt growth (TSMG) technique. Artificial holes were introduced to the green sample prior to thermal processing using a bespoke "spiked" mould. Mechanical properties such as elastic modulus, Vickers hardness, compressive strength and tensile strength were measured and compared to the properties of a standard bulk. The presence of the holes the bulk microstructure was observed to limit porosity and lower the concentration of macro-cracks in the bulk microstructure, resulting in significantly enhanced mechanical properties of the bulk single grains. The elastic modulus of the perforated bulks was observed to exhibit an increase of more than $45 \%$ compared to the standard samples. Compressive and tensile strengths were also improved significantly in the samples containing artificial holes. Observed differences in Vickers hardness, on the other hand, were negligible. This could be due by the fact that the hardness is measured on a small surface area of the single grain sample, where the effect of lower porosity and lower concentration of macro-cracks is less relevant. The introduction of artificial holes to the bulk, single grain microstructure appears to be a very promising technology for the production of melt-textured bulk superconductors with enhanced mechanical properties.
\end{abstract}

Index Terms-Elasticity, high-temperature superconductors, material properties, yttrium barium copper oxide

\section{INTRODUCTION}

Y TTRIUM barium copper oxide (YBCO) processed in the form of large, single domain bulk samples that can trap large magnetic fields has considerable potential for a wide range of engineering applications [1-5]. Studies of the mechanical properties of these technologically important materials, which are critical to their application at high field, however, has been relatively few, however, since the discovery of YBCO in 1987.

The most common technique used to characterize the mechanical properties of YBCO has been based on indentation at the macro, micro and nano-scales. This technique, however, only yields information about the external surface of the test

Manuscript receipt and acceptance dates will be inserted here. This work was financially supported by the Ministry of Industry and Trade of the Czech Republic (project TRIO FV10522).

T. Hlásek and V. Plecháček are with the CAN SUPERCONDUCTORS, Ringhofferova 66, Kamenice, 251 68, Czech Republic (e-mail: tomas.hlasek@can-superconductors.com and vladimir.plechacek@can-superconductors.com, respectively).

K.Y. Huang, J. H. Durrell and D.A. Cardwell are with Department of Engineering, University of Cambridge, Trumpington Street, Cambridge CB2 1PZ, UK (e- specimen, which does not necessarily correlate with the properties throughout the bulk material. In addition, some previous studies have indicated a dependency of the measured hardness on force, which contradicts the fact that the elastic modulus is an intrinsic material property of each sample and should depend only on the composition of the material. In consequence, the results of previous studies have a high variability; the elastic modulus varies between 10 and $300 \mathrm{GPa}$ and Vickers hardness between 0.5 and $20 \mathrm{GPa}$ [6]. This variability is clearly affected significantly by the measuring technique and the quality of the sample microstructure [7].

Understanding mechanics of bulk YBCO is critical for high field engineering applications $[8,9]$. The most common ways to improve the mechanical properties of REBCO bulk are Ag addition [10-12] and/or elimination of oxygenation cracking $[13,14]$. To evaluate the enhancement the uniaxial compression tests are important, therefore, in that they provide a relatively simple and effective way of characterizing the macroscopic response of the bulk material. The stress-strain profile can be calculated from these measurements, which yields information about applied force and the associated compressive displacement in the direction along which it is applied. The elastic modulus of the sample can also be determined from such measurements. In addition, monitoring the applied force up to the point of failure determines the ultimate tensile strength of the material.

We present the results of measurements of the fundamental mechanical properties of batch-processed YBCO bulk superconductors containing artificial holes. The results, which are compared to the properties of standard bulk YBCO sample prepared without holes, could serve as an effective starting point for further optimization and engineering studies of these critical properties of bulk, single grain YBCO superconductors.

mail: kyh30@cam.ac.uk,jhd25@cam.ac.uk and dc135@cam.ac.uk, respectively).

J. Esnoz-Larraya is with MAG SOAR SL, Av Europa $n^{\circ}$ 82, Valdemoro, 28341, Spain (e-mail: jesnoz@magsoar.com).

I. Valiente-Blanco is with MAG SOAR SL, Av Europa $n^{\circ} 82$, Valdemoro, 28341, Spain (e-mail: ivaliente@uah.es).

Color versions of one or more of the figures in this paper are available online at http://ieeexplore.ieee.org.

Digital Object Identifier will be inserted here upon acceptance. 


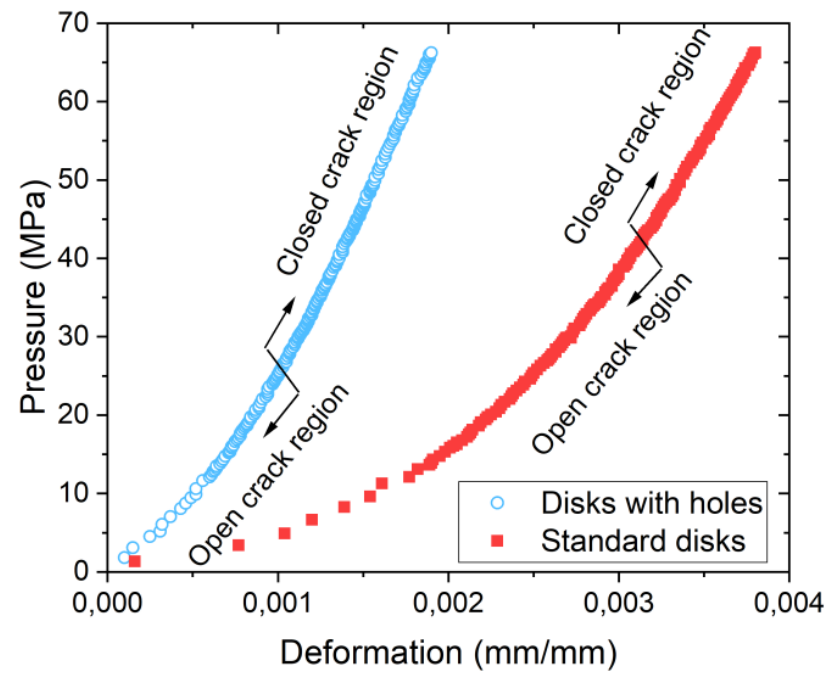

Fig. 1. Pressure vs deformation data for discs processed with and without artificial holes at room temperature.

\section{EXPERIMENTAL}

\section{A. Sample preparation}

Precursor powder with stoichiometric composition of $\mathrm{Y}_{1.8} \mathrm{Ba}_{2.4} \mathrm{Cu}_{3.4} \mathrm{O}_{\mathrm{x}}+0.5 \mathrm{w} \% \mathrm{CeO}_{2}$ was prepared by conventional solid-state reaction. Raw materials $\mathrm{Y}_{2} \mathrm{O}_{3}, \mathrm{BaCO}_{3}, \mathrm{CuO}$ and $\mathrm{CeO}_{2}$ with purities of $99.8+\%$ were mixed together and calcined in batches of approximate mass $15 \mathrm{~kg}$. Calcination was performed in four steps at temperatures of $850{ }^{\circ} \mathrm{C}-880{ }^{\circ} \mathrm{C}$ with intermediate homogenization of the partially-reacted precursor powder. A special "spiked" tool was designed and manufactured to enable the direct pressing of pellets with holes. $42 \mathrm{~g}$ of YBCO powder was pressed uniaxially into discs of diameter of $32 \mathrm{~mm}$ using the "spiked die" with holes of diameter $1.1 \mathrm{~mm}$ and an average hole to hole distance of $5 \mathrm{~mm}$ prior to melt processing. A reference batch of discs without holes was also prepared for purposes of comparison. Each single grain was fabricated by TSMG in air under isothermal processing conditions using commercial thin films of $\mathrm{Nd}-123$ on $\mathrm{MgO}(2 \times 2 \mathrm{~mm})$ as single crystal seeds. The temperature profile was optimised to avoid the formation of macroscopic cracks in the bulk microstructure and the unwanted nucleation of secondary grains. The large, single grains produced by the TSMG process were then annealed in flowing oxygen between temperatures $300{ }^{\circ} \mathrm{C}$ and $450{ }^{\circ} \mathrm{C}$ for $150 \mathrm{~h}$. Finally, each disc was machined precisely to a diameter of $28 \mathrm{~mm}( \pm 0.05 \mathrm{~mm})$ and a thickness of $10 \mathrm{~mm}$ $( \pm 0.02 \mathrm{~mm})$.

\section{B. Sample characterization}

The elastic modulus of each bulk sample was measured using test equipment based on a hydraulic press UNICRAFT WPP $20 \mathrm{E}$, which is capable of exerting a compressional force up to 20 tonnes. The applied force was recorded by a model SX-3 load cell, which is sensitive up to a maximum load of 10 tonnes. The resulting displacements were measured using a MarCator

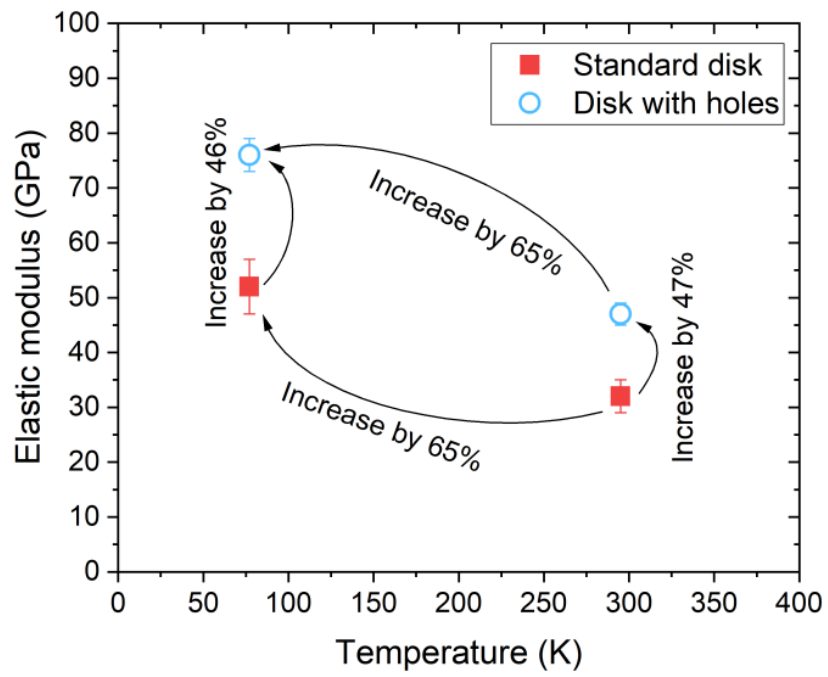

Fig. 2. Average values of elastic modulus in the closed crack region for both types of samples at 295 and $77 \mathrm{~K}$.

digital indicator, with a resolution of $5 \mu \mathrm{m}$. The data extracted from the digital indicator and the load cell were processed using a National Instrument NI 9209 data acquisition board with 24bit resolution. The mechanical properties of bulk YBCO are ceramic-like, and hence undergo relatively little deformation when exposed to a load. As a result, seven samples were stacked axially to perform the compression test, which was subjected to a compression force of approximately 5 tonnes. It was assumed that the cross-sectional area of the material does not change during compression, so an undistorted diameter of $28 \mathrm{~mm}$ was used subsequently for all samples in calculating the physical properties of the material. A minimum of 6 iterations were used to improve the statistical significance of the measurements. Each sample was characterized at two different temperatures; $295 \mathrm{~K}$ and $77 \mathrm{~K}$ (cooling was achieved using liquid nitrogen).

Vickers hardness was measured using a stationary diamond intender connected to the load cell model SX-1 (30 kg, accuracy class C3). Each sample was positioned over a motorized lab jack model L490MZ Thorlabs, which produced and recorded the relative displacement parallel to the $y$-axis. The displacement along the $x$-axis was generated by the linear guide and the distance between indentations was measured by the MarCator digital indicator with a resolution of $5 \mu \mathrm{m}$. The data generated by the sensors were processed by the National Instrument NI 9209 data acquisition board.

The cylindrical bulk samples were compressed along their diameter, along the growth sector boundaries and between two flat, aligned steel jaws with a crosshead speed of $0.03 \mathrm{~mm} / \mathrm{min}$,

TABLE I

SUMMARY OF ELASTIC MODULUS AND TENSILE STRENGTH

\begin{tabular}{lccc}
\hline \hline \multicolumn{1}{c}{ Sample } & $\mathrm{T}(\mathrm{K})$ & $\begin{array}{c}\text { Elastic modulus } \\
(\mathrm{GPa})\end{array}$ & $\begin{array}{c}\text { Ultimate Tensile } \\
\text { Strength }(\mathrm{GPa})\end{array}$ \\
\hline Standard & 295 & $32 \pm 3$ & $360 \pm 60$ \\
With holes & 295 & $47 \pm 2$ & $460 \pm 40$ \\
Standard & 77 & $52 \pm 5$ & $390 \pm 60$ \\
With holes & 77 & $76 \pm 3$ & $460 \pm 50$ \\
\hline
\end{tabular}




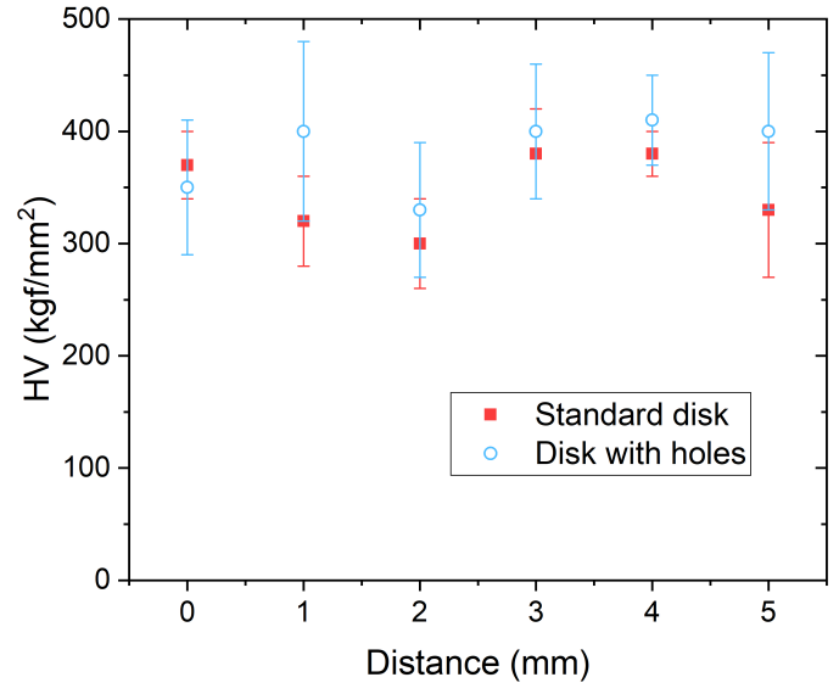

Fig. 3. The Vickers hardness profile measured at $295 \mathrm{~K}$. A distance of $0 \mathrm{~mm}$ is defined as the position of the seed, with distance increasing along the $c$-axis from the seed.

until failure occurred. The speed of the crosshead was sufficiently slow to ensure quasi-static loading throughout the measurement process. The indirect tensile strength $\sigma$ was calculated via equation: $\sigma=2 P / \pi D t$, where $P$ is the load at failure, $D$ is the diameter of the disc, and $t$ is the thickness of the disc.

\section{RESULTS AND DISCUSSION}

\section{A. Tensile strength}

The ultimate tensile strength was determined from the pressure observed at the sample breaking point (load parallel to $c$ axis). The averaged values of the ultimate tensile strength (Table I) of discs prepared with artificial holes are higher compared to standard disks. The sample to sample variation is higher compared to the variations in elastic modulus, so no clear conclusions can be drawn from these data.

\section{B. Elastic modulus}

The elastic modulus was calculated in the closed crack region from the slope of the linear part of the deformation curve. Fig. 1 shows examples of deformation curves for standard discs and discs processed with artificial holes (with pressure applied parallel to the $c$-axis of the superconductor) at room temperature. It can be seen that the open crack region (i.e. the non-linear part of the curve) is much larger in the case of the standard samples. This can be explained by the higher concentration and size of $\mathrm{a} / \mathrm{b}$-macro cracks present in standard YBCO. The differences in elastic modulus in the closed crack region of samples fabricated with and without artificial holes could be caused by the different porosity and intrinsic distribution of green phase $\left(\mathrm{Y}_{2} \mathrm{BaCuO}_{5}\right.$ or $\left.\mathrm{Y}-211\right)$ in the continuous $\mathrm{YBa}_{2} \mathrm{Cu}_{3} \mathrm{O}_{7}(\mathrm{Y}-123)$ phase matrix. The measured values of elastic moduli and ultimate tensile strength are summarized in Table I. Fig. 2 shows the measured relationship between the average values of elastic moduli for the two types of superconductor (processed with and
TABLE II

SUMMARY OF INDIRECT TENSILE STRENGTH

\begin{tabular}{lcc}
\hline \multicolumn{1}{c}{ Sample } & $\mathrm{T}(\mathrm{K})$ & $\sigma(\mathrm{MPa})$ \\
\hline Standard disks & 295 & 19.6 \\
Disks with artificial holes & 295 & 22.5 \\
Disks with artificial holes filled with Stycast & 295 & 27.8 \\
\hline
\end{tabular}

without holes) and at the two different temperatures. It can be seen that the elastic modulus increases by $65 \%$ for both sample types when the temperature of the measurement decreases to 77 $\mathrm{K}$. It is also interesting to observe that the elastic modulus increases by approximately $46 \%$ at both measured temperatures for the samples processed with artificial holes.

\section{Hardness and hardness profiles}

The Vickers hardness was measured at at least five points at a/b-plane for each sample. Firstly, the hardness of the standard single grains and the single grains processed with artificial holes was compared at the top surface near the thin film seed. The measurement was then repeated after removal by grinding of $1 \mathrm{~mm}$ of material of the thickness of each disc (i.e. along the $c$-axis), with the results summarized in the Fig.3. It can be seen that the hardness is slightly higher in the case of the sample containing the holes, although any difference lies generally within the range of error bars. It can also be seen that the hardness follows a similar trend with increasing distance from the top surface of the bulk single grain.

Finally, the difference in hardness between the standard and perforated discs is more pronounced at liquid nitrogen temperature $(77 \mathrm{~K})$. The average value of the hardness was $540 \pm 60 \mathrm{kgf} / \mathrm{mm}^{2}$ and $630 \pm 40 \mathrm{kgf} / \mathrm{mm}^{2}$ for the standard and the perforated discs, respectively, and the hardness increased by $50-80 \%$ when measured at $77 \mathrm{~K}$. These data are comparable with values of Y123/Ag published by Fujimoto [15].

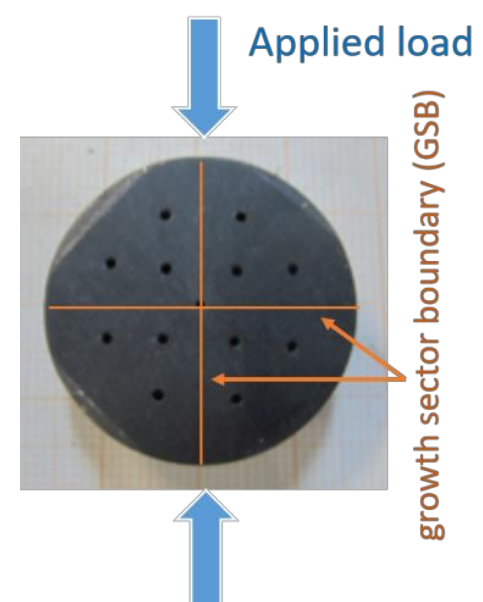

Fig. 4. Indirect measurement of tensile strength. The arrows shows the exact point at which the load is applied (i.e. parallel to the $a / b$-plane of the superconductor and the growth sector boundary) 


\section{Indirect tensile stress and modifications}

The orientation of the samples for the indirect tensile strength measurements is shown in Fig. 4. In contrast with the measurement of the elastic modulus and ultimate tensile strength, the direction of applied load is perpendicular to the $c$-axis of the bulk superconductor. The load was applied along the growth sector boundary for all samples measured. The standard samples and the samples containing artificial holes were measured in the first round of tests. The average values of indirect tensile strength are summarized in Table II, which reveal $15 \%$ enhancement in the strength in the samples prepared with holes compared to the standard bulk samples.

The second set of samples studied was prepared by filling the artificial holes with Stycast epoxy resin (Stycast 2850 FT with 23 LV catalyst). These samples were observed to exhibit a further increase in strength by $23 \%$ compared to the samples containing unfilled holes. This approach could enhance even further the mechanical properties of single grain YBCO samples when the elasticity and thermal expansivity of the filler material are chosen to match the properties of YBCO.

\section{CONCLUSION}

The benefits of improving the mechanical properties of bulk YBCO superconductors by the introduction of artificial holes into the sample microstructure have been investigated and compared to the properties of standard bulk YBCO samples. The elastic modulus of the samples containing holes was improved by more than $45 \%$ at temperatures of $295 \mathrm{~K}$ and $77 \mathrm{~K}$. The ultimate tensile strength (for load applied parallel to sample $c$ axis) was also improved at room temperature from $360 \mathrm{GPa}$ to $460 \mathrm{GPa}$ for the single grains fabricated with artificial holes. This change was less pronounced at $77 \mathrm{~K}$, where the improvement was from $390 \mathrm{GPa}$ to $460 \mathrm{GPa}$ for the single grains fabricated with artificial holes. The effect of artificial holes on hardness was less pronounced compared to increase in strength and elastic modulus, except at $77 \mathrm{~K}$ where the difference was more pronounced. An increase in the average value of indirect tensile strength (for force applied perpendicular to the $c$-axis) of $15 \%$ for samples containing artificial holes was also observed. The results of this measurement suggest there is significant potential for further enhancing the mechanical properties of bulk YBCO by filling the holes by material with appropriate, matched physical properties. Such technology would further enable the thermal conductivity to be adjusted and improve the applications potential and stability of the materials. This feature could lead potentially to an improvement of superconducting properties in applications that utilise pulsed field magnetization, in particular.

\section{ACKNOWLEDGMENT}

The authors would like to thank J. Plecháček for project supervision and management. The authors would also like to thank J. Nohava and J. Kašpar for workshop support in sample machining.

\section{REFERENCES}

[1] J.H. Durrell, A.R. Dennis, J. Jaroszynski, M.D. Ainslie, K.G.B. Palmer, Y.H. Shi, A.M. Campbell, J. Hull, M. Strasik, E.E. Hellstrom and D.A. Cardwell, "A trapped field of $17.6 \mathrm{~T}$ in melt-processed, bulk $\mathrm{Gd}-\mathrm{Ba}-\mathrm{Cu}-$ O reinforced with shrink-fit steel," Supercond. Sci. Tech., 2014, 27, (8), pp. 082001

[2] F.N. Werfel, U. Floegel-Delor, R. Rothfeld, T. Riedel, B. Goebel, D. Wippich and P. Schirrmeister, "Superconductor bearings, flywheels and transportation," Supercond. Sci. Tech., 2012, 25, (1), pp. 014007

[3] T. Hlásek, V. Plecháček, "Trapped field in different shapes of RE-ba-cuo single grains for the use in production of superconducting bearings," IEEE Trans. Appl. Supercond., vol. 25, no. 3, Jun. 2015, Art. No. 6800504

[4] F.N. Werfel, U. Floegel-Delor, T. Riedel, B. Goebel, R. Rothfeld, P. Schirrmeister and D. Wippich, "Large-scale HTS bulks for magnetic application,” Physica C: Supercond., 2013, 484, pp. 6-11

[5] I. Valiente-Blanco, E. Diez-Jimenez, C. Cristache, M. A. AlvarezValenzuela, J. L. Perez-Diaz, "Characterization and Improvement of Axial and Radial Stiffness of Contactless Thrust Superconducting Magnetic Bearings," Tribology Lett., vol. 54, Issue 3, Jun. 2014, pp 213220

[6] J.J. Roa, F.T. Dias and M. Segarra (2012). Magnetical Response and Mechanical Properties of High Temperature Superconductors, YBaCu3O7-X Materials, Superconductors - Properties, Technology, and Applications, Dr. Yury Grigorashvili (Ed.), ISBN: 978-953-51-0545-9, InTech.

[7] O. Sahin, "Indentation Load Effect on Young's Modulus and Hardness of Porous Sialon Ceramic by Depth Sensing Indentation Tests," Chinese Phys. Lett., vol. 24, no. 11, Nov. 2007, pp 3206.

[8] Y. Ren, R. Weinstein, J. Liu, R. P. Sawh and C. Foster, "Damage caused by magnetic pressure at high trapped field in quasi-permanent magnets composed of melt-textured $\mathrm{Y}-\mathrm{Ba}-\mathrm{Cu}-\mathrm{O}$ superconductor," Physica C: $\mathrm{Su}$ percond., 1995, 251(1-2), 15-26.

[9] G. Fuchs, G. Krabbes, P. Schätzle, S. Gru $\beta$, P. Stoye, T. Staiger, K.-H. Mu"ller, J. Fink, and L. Schultz, "High trapped fields in bulk YBa2Cu3O7- $\delta$ samples at temperatures around $50 \mathrm{~K}$," Appl. Phys. Lett., 1997, 70(1), 117-119

[10] T Miyamoto, K Nagashima, N Sakai and M Murakami, "Mechanical properties of bulk superconductors," Supercond. Sci. Tech., 2000, 13, 6, 816-819

[11] H Fujimoto and A Murakami, "Mechanical properties of Gd123 superconducting bulks at 77 K," Supercond. Sci. Tech., 2012, 25, 5, 054017

[12] P. Diko, G. Fuchs and G. Krabbes, "Influence of silver addition on cracking in melt-grown YBCO," Physica C Supercond., 2001, 363(1), 60-66.

[13] P. Diko, X. Chaud, V. Antal, M. Kaňuchová, M. Sefčíková and J Kováč, "Elimination of oxygenation cracks in top-seeded melt-growth YBCO superconductors by high pressure oxygenation," Supercond. Sci. Tech., 2008, 21, 11, 115008

[14] D. Isfort, X. Chaud, R. Tournier and G. Kapelski, "Cracking and oxygenation of $\mathrm{YBaCuO}$ bulk superconductors: application to c-axis elements for current limitation," Physica C Supercond., 2003, 390, 4, 341-355

[15] H. Fujimoto, "Mechanical Properties of Y123/Ag Superconducting Bulks," IEEE Trans. Appl. Supercond. 16, 2, 1043-1046 